\title{
Risk factors for revascularization and in-stent restenosis in patients with triple-vessel disease after second-generation drug-eluting stent implantation: a retrospective analysis
}

MengYing Zeng, XiaoWei Yan ${ }^{*}$ and Wei Wu

\begin{abstract}
Objectives: Coronary artery disease (CAD) is a common cardiac disease with high morbidity and mortality, and triple-vessel disease (TVD) is a severe type of CAD. This study investigated risk factors for revascularization and in-stent restenosis (ISR) in TVD patients who underwent second-generation drug-eluting stent implantation.

Methods: A retrospective clinical study was conducted, and 246 triple-vessel disease (TVD) patients with 373 vessels after second-generation drug-eluting stent (DES) implantation who received follow-up coronary angiography (CAG) were consequently enrolled. According to the follow-up angiography, patients were categorized into the revascularization group and nonrevascularization group as well as the in-stent restenosis (ISR) group and non-ISR group. Univariate and multivariate logistic regression analyses were used to identify risk factors for revascularization and ISR. Receiver operating characteristic (ROC) curve with area under the curve (AUC) analysis was performed to assess the predictive power of these risk factors.

Results: In the median follow-up period of $28.0(14.0,56.0)$ months, 142 TVD patients $(57.7 \%)$ with 168 vessels underwent revascularization, and ISR occurred in 43 TVD patients (17.5\%) with 47 vessels after second-generation DES implantation. Compared to the nonrevascularization group, the revascularization group presented with an increased rate of current smoking and higher levels of TC, LDL-C, HDL-C, non-HDL-C, ApoB, neutrophils, and Hs-CRP as well as a longer follow-up of months but with a lower level of HDL-C. In addition, patients in the ISR group had an older age, longer follow-up (months) and elevated rates of current smoking and stage 4-5 chronic kidney disease (CKD4-5). In multivariate analysis, current smoking and higher non-HDL-c were independent risk factors for revascularization. In addition, older age, current smoking and CKD4-5 were considered independent risk factors for ISR. Importantly, the receiver operating characteristic curve showed that non-HDL-C and age displayed predictive power for revascularization and ISR, respectively.
\end{abstract}

Conclusion: Current smoking is an independent risk factor for both revascularization and in-stent restenosis. Higher non-HDL-c is independently related to revascularization; moreover, increased age and CKD4-5 are potential risk factors for ISR in TVD patients after second-generation drug-eluting stent implantation.

*Correspondence: yanxwpumch@163.com

Department of Cardiology, Peking Union Medical College Hospital

(Dongdan Campus), Chinese Academy of Medical Sciences \& Peking

Union Medical College, No. 1 Shuaifuyuan Wangfujing Dongcheng

District, Beijing 100730, China

(c) The Author(s) 2021. Open Access This article is licensed under a Creative Commons Attribution 4.0 International License, which permits use, sharing, adaptation, distribution and reproduction in any medium or format, as long as you give appropriate credit to the original author(s) and the source, provide a link to the Creative Commons licence, and indicate if changes were made. The images or other third party material in this article are included in the article's Creative Commons licence, unless indicated otherwise in a credit line to the material. If material is not included in the article's Creative Commons licence and your intended use is not permitted by statutory regulation or exceeds the permitted use, you will need to obtain permission directly from the copyright holder. To view a copy of this licence, visit http://creativecommons.org/licenses/by/4.0/. The Creative Commons Public Domain Dedication waiver (http://creativeco mmons.org/publicdomain/zero/1.0/) applies to the data made available in this article, unless otherwise stated in a credit line to the data. 
Keywords: Triple-vessel coronary artery disease, Revascularization, In-stent restenosis, Second-generation drugeluting stents, Risk factors

\section{Introduction}

Coronary artery disease (CAD) is a leading cause of death worldwide. Triple-vessel disease (TVD) is defined as $\geq 50 \%$ narrowing in all three major epicardial coronary arteries (left anterior descending artery, LAD; left circumflex artery, LCX; right coronary artery, RCA) with or without left main coronary artery disease (LM), which is a severe type of CAD. Additionally, TVD is regarded as an independent predictor of major adverse cardiac events (MACEs) and all-cause mortality [1, 2]. Over the past two decades, percutaneous coronary intervention (PCI) has become a primary modality for coronary revascularization, even for TVD patients. Drug-eluting stents (DESs) in patients with CAD (acute coronary syndrome or stable angina) can improve clinical outcomes when compared to bare-metal stents [3] but the occurrence rate of angiographic stenotic progression, such as revascularization and in-stent restenosis, remains high in CAD patients, especially for late or very late restenosis [4]. Some studies have explored ISR risk or risk factors for revascularization in CAD patients after PCI, indicating that dyslipidemia, diabetes mellitus, hypersensitive C-reactive protein, smoking and homocysteine, vessel size and complex lesion morphology were closely associated with ISR and revascularization [5-8]. However, little is known about the risk factors for revascularization and ISR in TVD patients after second-generation DES implantation. Therefore, we conducted this study to investigate the risk factors in these patients.

\section{Materials and methods Study patients}

Patients with TVD after second-generation DES implantation who received follow-up CAG at the Department of Cardiology, Peking Union Medical College Hospital between February 2015 and November 2020 were consecutively enrolled in this retrospective study. The inclusion criteria were as follows: (a) patients diagnosed with TVD and at least one of the 3 major coronary arteries underwent second-generation DES implantation, (b) age older than 18 years old, (c) patients receiving followup CAG after the previous procedure, and (d) patients receiving dual antiplatelet therapy (DAPT). The exclusion criteria were as follows: (a) severe liver dysfunction disease; (b) combined myocarditis, congenital heart disease, valvular diseases, cardiomyopathy, autoimmune disease, malignancies, infectious diseases and hyperthyroidism or hypothyroidism; (c) contraindications to aspirin, clopidogrel or ticagrelor; (d) follow-up CAG was not available; and (e) discontinuing antiplatelet therapy without medical advice. This study was approved by the Ethics Committee of Peking Union Medical College Hospital and performed in accordance with Declaration of Helsinki. Written informed consent was obtained from all patients.

\section{Data collection}

Baseline parameters, including demographic information, risk factors related to CAD (hypertension, diabetes mellitus, family history of CAD, CKD, current smoking and alcohol intake), laboratory tests (lipid profile, in which, non-HDL-c was calculated by subtracting the HDL-c level from the TC level, neutrophils, lymphocytes, white blood cells [WBCs], hypersensitive C-reactive protein [hs-CRP], glycosylated hemoglobin A1c [HbA1c] and homocysteine, serum uric acid [SUA]), were collected before the follow-up CAG. The follow-up time and CAG findings were also included. Second generation DES were used in our patients, including sirolimus-eluting stents (Microport, Shanghai, China and Jiwei, Shandong, China), everolimus-eluting stents (Boston Scientific, Natick, Massachusetts, and Abbott Vascular, Santa Clara, California), and zotarolimus-eluting stents (Medtronic, Santa Rosa, California). To our knowledge, everolimuseluting stents and zotarolimus-eluting stents are used in current clinical practice worldwide.

\section{$\mathrm{PCl}$ and grouping}

After previous stent implantation, patients received $100 \mathrm{mg}$ aspirin and $75 \mathrm{mg}$ clopidogrel once daily or $90 \mathrm{mg}$ ticagrelor twice daily. Lesion progress and ISR in the follow-up CAG were evaluated by two independent interventional cardiologists. ISR was defined as percent diameter stenosis $\geq 50 \%$ in the stent at follow-up angiography. Revascularization was defined as receiving second revascularization in the same lesions or different lesions at follow-up angiography. Patients who required revascularization in follow-up were included in the revascularization group. Patients with ISR were included in the ISR group.

\section{Statistical analysis}

All statistical analyses were performed using SPSS (version 23), and continuous variables were reported as the mean \pm standard deviation $(\mathrm{X} \pm \mathrm{SD})$ or median (interquartile range) according to whether they were normally 
distributed. Categorical variables were expressed as frequencies [n, (\%)]. Intergroup measurement comparisons were performed using t-tests or Wilcoxon rank sum tests, and counts were compared by chi-square tests. Univariate logistic regression analysis and multivariate logistic regression model analysis were used to determine risk factors for revascularization and ISR with odds ratios (ORs) and 95\% confidence intervals (CIs). Receiver operating characteristic (ROC) curve with area under the curve (AUC) analysis was performed to assess the predictive power of risk factors for revascularization and ISR. All $P$ values were two-sided, and $P<0.05$ was considered statistically significant.

\section{Results}

\section{TVD patient characteristics}

Over a median follow-up of 28 (14.0, 56.0) months, the study enrolled 246 TVD patients (373 vessels) who underwent follow-up CAG after second-generation DES stent implantation (Fig. 1), of whom $70.7 \%$ were men. The mean age was $64.3 \pm 10.0$ years. A total of 202 (82.1\%) patients received follow-up CAG due to angina pectoris or precordial distress. In contrast, 44 (17.9\%) patients received routine follow-up CAG. According to the laboratory results, the patients' mean non-HDL$C$ was $2.63 \pm 0.81 \mathrm{mmol} / \mathrm{L}$, and the mean $\mathrm{LDL}-\mathrm{C}$ was $1.95 \pm 0.63 \mathrm{mmol} / \mathrm{L}$. In the previous $\mathrm{PCI}$ procedure, $37.8 \%$ of patients received two-vessel stenting, and $6.9 \%$ of patients underwent triple-vessel stenting. Other characteristics of TVD patients are shown in Table 1.

\section{Comparison of characteristics between revascularization group and nonrevascularization group as well as ISR group and non-ISR group}

A total of 142 patients (168 vessels) required revascularization according to the follow-up CAG, among which 4 patients were recommended to undergo coronary artery bypass graft (CABG) surgery. Compared to the nonrevascularization group, more patients in the revascularization group were current smokers $(46.5 \%$ versus $25.0 \%$, $P=0.001)$. The revascularization group had lower HDL-c levels $(0.97 \pm 0.22 \mathrm{mmol} / \mathrm{L}$ versus $1.05 \pm 0.26 \mathrm{mmol} / \mathrm{L}$, $P=0.004)$ but higher non-HDL-c $(2.80 \pm 0.75 \mathrm{mmol} / \mathrm{L}$ versus $\quad 2.40 \pm 0.66 \mathrm{mmol} / \mathrm{L}, \quad P<0.001), \quad$ TC $(3.76 \pm 0.90 \mathrm{mmol} / \mathrm{L}$ versus $3.44 \pm 0.74 \mathrm{mmol} / \mathrm{L}$, $P=0.005), \quad$ LDL-C $\quad(2.07 \pm 0.69 \quad \mathrm{mmol} / \mathrm{L}$

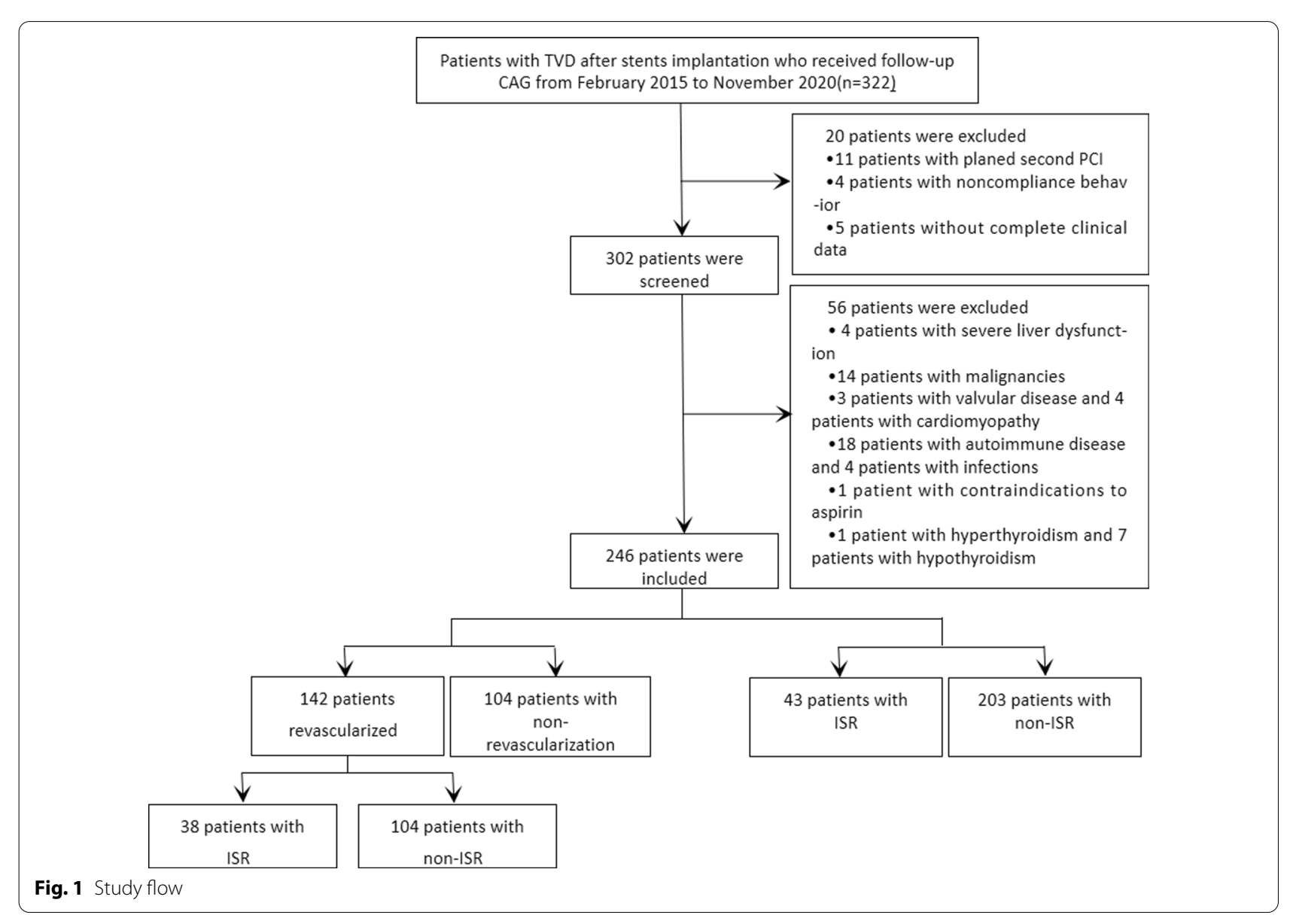


Table 1 Population characteristics of TVD patients who received follow-up CAG after second-generation DES implantation

\begin{tabular}{|c|c|c|c|c|c|c|c|}
\hline $\begin{array}{l}\text { Population } \\
\text { characteristics }\end{array}$ & $\begin{array}{l}\text { TVD patients } \\
(\mathrm{n}=246)\end{array}$ & $\begin{array}{l}\text { Revascularization } \\
\text { group }(n=142)\end{array}$ & $\begin{array}{l}\text { Nonrevascularization } \\
\text { group }(n=104)\end{array}$ & $P$ value & ISR group $(n=43)$ & $\begin{array}{l}\text { Non-ISR group } \\
(n=203)\end{array}$ & $p$ value \\
\hline Age (years) & $64.3 \pm 10.0$ & $63.8 \pm 9.9$ & $65.0 \pm 10.0$ & 0.340 & $67.3 \pm 10.2$ & $63.6 \pm 9.8$ & 0.029 \\
\hline Male $(\mathrm{n}, \%)$ & $174(70.7 \%)$ & $101(71.1 \%)$ & $73(70.2 \%)$ & 0.874 & 31 (72.1\%) & 143 (70.4\%) & 0.829 \\
\hline BMI $\left(\mathrm{kg} / \mathrm{m}^{2}\right)$ & $26.2 \pm 3.3$ & $26.2 \pm 3.4$ & $26.2 \pm 3.2$ & 0.948 & $26.1 \pm 2.9$ & $26.2 \pm 3.3$ & 0.858 \\
\hline $\begin{array}{l}\text { Current smoking } \\
(\mathrm{n}, \%)\end{array}$ & $92(37.4 \%)$ & 66 (46.5\%) & $26(25.0 \%)$ & $0.001^{*}$ & 22 (51.2\%) & 70 (34.5\%) & 0.040 \\
\hline $\begin{array}{l}\text { Current alcohol } \\
\text { intake }(n, \%)\end{array}$ & $66(26.8 \%)$ & 41 (28.9\%) & 25 (24.0\%) & 0.398 & $10(23.3 \%)$ & $56(27.6 \%)$ & 0.560 \\
\hline Hypertension (n, \%) & $186(75.6 \%)$ & $112(78.9 \%)$ & $74(71.2 \%)$ & 0.164 & 32 (74.4\%) & 154 (75.9\%) & 0.841 \\
\hline $\begin{array}{l}\mathrm{SBP}>140 \text { and/or } \\
\mathrm{DBP}>90(n, \%)\end{array}$ & $70(29.3 \%)$ & $38(26.8 \%)$ & $34(32.4 \%)$ & 0.312 & $10(23.3 \%)$ & $62(30.5 \%)$ & 0.340 \\
\hline Diabetes (n, \%) & $129(52.4 \%)$ & 81 (57.0\%) & 48 (46.2\%) & 0.091 & 24 (55.8\%) & 105 (51.7\%) & 0.626 \\
\hline $\begin{array}{l}\text { Family history of } \\
\text { CAD }(n, \%)\end{array}$ & $76(30.9 \%)$ & 45 (31.7\%) & 31 (29.8\%) & 0.752 & $12(27.9 \%)$ & 64 (31.5\%) & 0.641 \\
\hline CKD1-3 (n, \%) & $20(8.1 \%)$ & $13(9.2 \%)$ & $7(6.7 \%)$ & 0.492 & $5(11.6 \%)$ & $15(7.4 \%)$ & 0.356 \\
\hline CKD4-5 $(n, \%)$ & $9(3.7 \%)$ & $9(6.3 \%)$ & 0 & / & $4(9.3 \%)$ & $5(2.5 \%)$ & 0.030 \\
\hline $\begin{array}{l}\text { Angina pectoris or } \\
\text { precordial distress } \\
(n, \%)\end{array}$ & $202(82.1 \%)$ & $136(95.8 \%)$ & 66 (63.5\%) & $<0.001^{*}$ & 38 (88.4\%) & 164 (80.8\%) & 0.238 \\
\hline \multicolumn{8}{|l|}{ Laboratorytest } \\
\hline TC (mmol/L) & $3.63 \pm 0.84$ & $3.76 \pm 0.90$ & $3.44 \pm 0.74$ & $0.005^{*}$ & $3.84 \pm 1.04$ & $3.58 \pm 0.79$ & 0.073 \\
\hline LDL-C (mmol/L) & $1.95 \pm 0.63$ & $2.07 \pm 0.69$ & $1.79 \pm 0.51$ & $0.001^{*}$ & $2.00 \pm 0.75$ & $1.94 \pm 0.61$ & 0.552 \\
\hline $\mathrm{HDL}-\mathrm{C}(\mathrm{mmol} / \mathrm{L})$ & $1.00 \pm 0.24$ & $0.97 \pm 0.22$ & $1.05 \pm 0.26$ & $0.004^{*}$ & $1.01 \pm 0.30$ & $0.99 \pm 0.23$ & 0.674 \\
\hline $\begin{array}{l}\text { Non-HDL-C } \\
(\mathrm{mmol} / \mathrm{L})\end{array}$ & $2.63 \pm 0.81$ & $2.80 \pm 0.75$ & $2.40 \pm 0.66$ & $<0.001^{*}$ & $2.83 \pm 1.05$ & $2.59 \pm 0.75$ & 0.083 \\
\hline ApoB (g/L) & $0.74 \pm 0.20$ & $0.77 \pm 0.20$ & $0.70 \pm 0.18$ & $0.009^{*}$ & $0.74 \pm 0.19$ & $0.74 \pm 0.20$ & 0.788 \\
\hline $\operatorname{NEU}\left(\times 10^{9}\right)$ & $4.39 \pm 1.40$ & $4.59 \pm 1.48$ & $4.11 \pm 1.23$ & $0.008^{*}$ & $4.72 \pm 1.46$ & $4.31 \pm 1.38$ & 0.078 \\
\hline $\operatorname{LY}\left(\times 10^{9}\right)$ & $1.82 \pm 0.69$ & $1.80 \pm 0.66$ & $1.82 \pm 0.73$ & 0.874 & $1.80 \pm 0.65$ & $1.81 \pm 0.70$ & 0.923 \\
\hline NLR & $2.40(1.88,3.08)$ & $2.43(1.91,3.29)$ & $2.26(1.81,2.86)$ & 0.120 & $2.50(2.11,3.58)$ & $2.39(1.86,3.05)$ & 0.179 \\
\hline WBC $\left(\times 10^{9}\right)$ & $6.82 \pm 1.82$ & $7.04 \pm 1.83$ & $6.52 \pm 1.79$ & 0.672 & $7.15 \pm 1.95$ & $6.74 \pm 1.80$ & 0.184 \\
\hline $\mathrm{Hs}-\mathrm{CRP}(\mathrm{mg} / \mathrm{L})$ & $0.96(0.43,2.22)$ & $1.22(0.53,2.68)$ & $0.83(0.39,1.88)$ & $0.022^{*}$ & $1.38(0.70,3.23)$ & $0.92(0.40,2.15)$ & 0.066 \\
\hline HbA1c (\%) & $6.3(5.8,7.3)$ & $6.4(5.8,7.8)$ & $6.2(5.8,6.8)$ & 0.090 & $6.4(6.0,8.4)$ & $6.2(5.8,7.1)$ & 0.050 \\
\hline SUA ( $\mu \mathrm{mol} / \mathrm{L})$ & $351(296,403)$ & $357(297,409)$ & $339 \pm 78$ & 0.320 & $341(289,401)$ & $354(299,405)$ & 0.680 \\
\hline \multicolumn{8}{|l|}{ Previous findings } \\
\hline $\operatorname{ACS}(n / \%)$ & $154(62.6 \%)$ & $88(62.0 \%)$ & $66(63.5)$ & 0.811 & $19(44.2 \%)$ & $73(36.0 \%)$ & 0.311 \\
\hline $\begin{array}{l}\text { Target vessel at LM } \\
(\mathrm{n} / \%)\end{array}$ & $22(8.9 \%)$ & $9(5.3 \%)$ & $13(12.5 \%)$ & 0.094 & $2(4.7 \%)$ & $20(9.9 \%)$ & 0.278 \\
\hline $\begin{array}{l}\text { Target vessel at LAD } \\
\text { only }(\mathrm{n} / \%)\end{array}$ & $63(25.6 \%)$ & $36(25.4 \%)$ & 27 (26.0\%) & 0.914 & $14(32.6 \%)$ & 49 (24.1\%) & 0.250 \\
\hline $\begin{array}{l}\text { Target vessel at LCX } \\
\text { only ( } \mathrm{n} / \%)\end{array}$ & $29(11.8 \%)$ & $18(12.7 \%)$ & $11(10.6 \%)$ & 0.614 & $0(0 \%)$ & $29(4.3 \%)$ & / \\
\hline $\begin{array}{l}\text { Target vessel at RCA } \\
\text { only ( } \mathrm{n} / \%)\end{array}$ & 45 (18.3\%) & $26(18.3 \%)$ & 19 (18.3\%) & 0.994 & $6(14.0 \%)$ & 39 (19.2\%) & 0.418 \\
\hline $\begin{array}{l}\text { Two vessels stenting } \\
(\mathrm{n} / \%)\end{array}$ & 93 (37.8\%) & $53(37.3 \%)$ & 40 (38.5\%) & 0.856 & $18(41.9 \%)$ & 75 (36.9\%) & 0.546 \\
\hline $\begin{array}{l}\text { Triple vessels stent- } \\
\text { ing }(n / \%)\end{array}$ & $17(6.9 \%)$ & $10(7.0 \%)$ & $7(6.7 \%)$ & 0.924 & $5(11.6 \%)$ & $12(5.9 \%)$ & 0.179 \\
\hline SYNTAX score & $12.9 \pm 4.5$ & $13.4 \pm 4.7$ & $12.4 \pm 4.0$ & 0.085 & $12.6 \pm 5.3$ & $13.0 \pm 4.3$ & 0.558 \\
\hline $\begin{array}{l}\text { Everolimus/zotaroli- } \\
\text { mus-eluting stents } \\
\text { (n/\%) }\end{array}$ & $184(74.8 \%)$ & 107 (75.4\%) & 77 (74.0\%) & 0.815 & 31 (72.3\%) & $153(75.4 \%)$ & 0.653 \\
\hline $\begin{array}{l}\text { Time of follow-up } \\
\text { (months) }\end{array}$ & $28.0(14.0,56.0)$ & $16.8(38.0,63.0)$ & $23.5(13.0,48.5)$ & $0.002^{*}$ & $39.0(22.0,78.0)$ & $27.0(14.0,53.0)$ & $0.024 \bullet$ \\
\hline
\end{tabular}


Table 1 (continued)

Data are presented as the mean $\pm \mathrm{SD}$, median (interquartile range) and (n/\%)

TVD triple-vessel disease, CAG coronary angiography, DES drug-eluting stents, ISR in-stent restenosis, BMI body mass index, SBP systolic blood pressure, DBP diastolic blood pressure, $C A D$ coronary artery disease, $C K D$ chronic kidney disease, $T C$ total cholesterol, $L D L-C$ low-density lipoprotein cholesterol, $H D L-C$ high-density lipoprotein cholesterol, non-HDL-C non-high-density lipoprotein cholesterol, $A p o B$ apolipoprotein B, NEU neutrophil, LY lymphocyte, NLR neutrophil-to-lymphocyte ratio, WBC white blood cell, Hs-CRP high-sensitivity C-reactive protein, HbA1c glycosylated hemoglobin A1C, HCY homocysteine, SUA serum uric acid, LM left main coronary artery disease, $L A D$ left anterior descending branch, $L C X$ left circumflex artery RCA, right coronary artery

${ }^{*} P<0.05$, compared with nonrevascularization cases; $\cdot P<0.05$, compared with non-ISR cases

versus $1.79 \pm 0.51 \mathrm{mmol} / \mathrm{L}, \quad P=0.001)$ and $\mathrm{ApoB}$ $(0.77 \pm 0.20 \mathrm{mmol} / \mathrm{L}$ versus $0.70 \pm 0.18 \mathrm{mmol} / \mathrm{L}$, $P=0.009)$ levels than the nonrevascularization group. Moreover, in the revascularization group, patients had higher counts of neutrophils $(\mathrm{P}=0.008)$ and hsCRP $(P=0.022)$ as well as more months of follow-up $(P=0.002)$. In total, 43 patients (47 vessels) were confirmed as ISR. Compared to the non-ISR group, patients were older in the ISR group $(67.3 \pm 10.2$ versus $63.6 \pm 9.8$, $P=0.029)$. Furthermore, ISR patients had a higher percentage of current smokers $(P=0.040)$ and CKD4-5
$(P=0.030)$ than non-ISR patients. In addition, the follow-up time was longer in the ISR group compared with the non-ISR group $(P=0.024)$. (Table 1$)$.

Revascularization and ISR rates at different follow-up times As illustrated in Fig. 2a and b, the percentages of revascularization and ISR were both the highest in the 1st to 2nd year after stent implantation with values of $12.6 \%$ (31 of 246 patients) and $4.1 \%$ (10 of 246 patients), respectively. On the one hand, the incidence of revascularization reached the second peak in the 6th to 7 th follow-up years. (a)

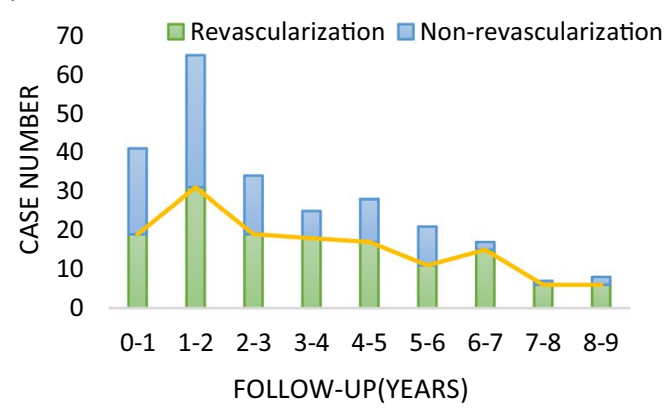

(c)

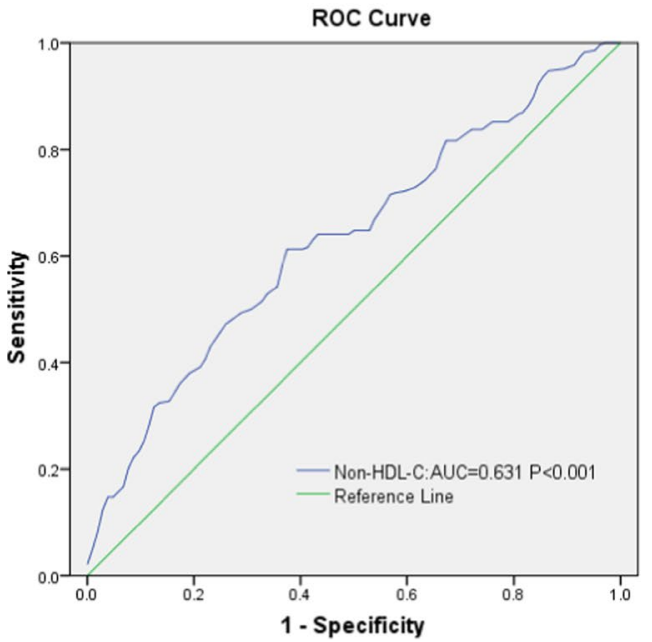

(b)

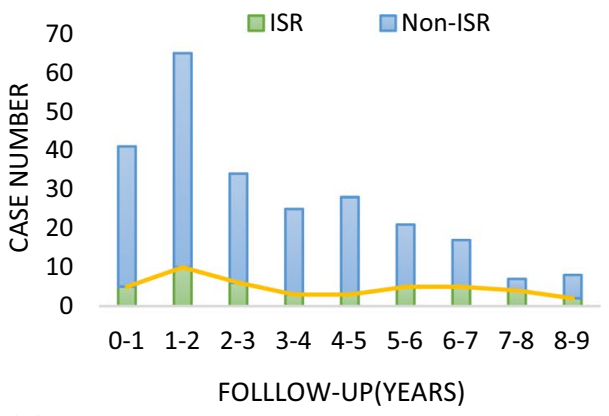

(d)

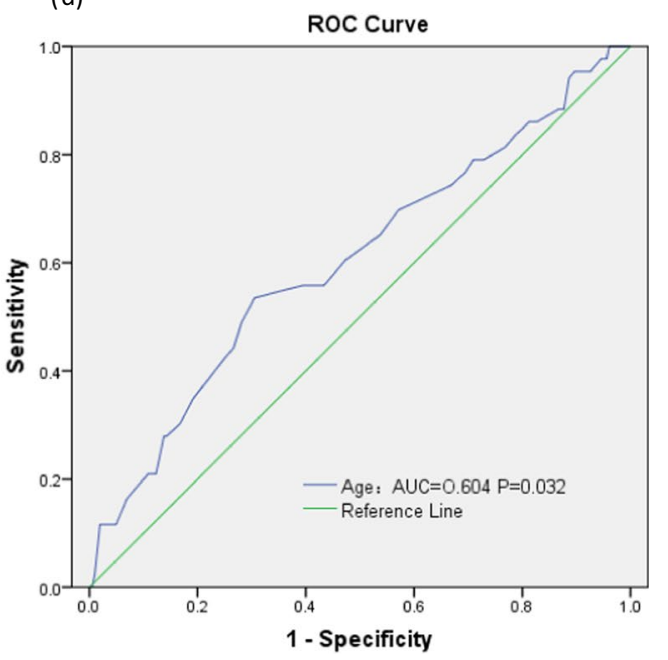

Fig. 2 a The number of cases of revascularization and nonrevascularization based on the follow-up duration in years; $\mathbf{b}$ The number of cases of in-stent restenosis and non-in-stent restenosis based on the follow-up duration in years. $\mathbf{c}$ Receiver operating characteristic (ROC) curve analysis of non-HDL-C for predicting revascularization; $\mathbf{d}$ Receiver operating characteristic (ROC) curve analysis of ages for predicting in-stent restenosis 
On the other hand, the rate of ISR gradually decreased with the prolongation of the follow-up time until the 5th to 6 th year.

\section{Logistic regression analysis of risk factors for revascularization}

Univariate logistic regression analysis revealed that current smoking $(P=0.001, \quad \mathrm{OR}=2.605, \quad 95 \% \quad \mathrm{CI}$ 1.499-4.529) was positively correlated with the risk of revascularization. We confirmed that TC $(P=0.006$, $\mathrm{OR}=1.591,95 \%$ CI $1.415-2.111)$, LDL-C $(P=0.001$, $\mathrm{OR}=2.153,95 \%$ CI $1.354-3.423)$, non-HDL-c $(P<0.001$, $\mathrm{OR}=1.994,95 \%$ CI $1.378-2.887)$, ApoB $(P=0.010$, $\mathrm{OR}=7.549,95 \%$ CI $1.610-35.405)$, NEU $(P=0.010$, $\mathrm{OR}=1.301,95 \% \mathrm{CI} 1.066-1.588)$ and follow-up time $(P=0.002, \mathrm{OR}=1.017,95 \%$ CI $1.006-1.027)$ were positively related to revascularization risk. In contrast, HDL-c $(P=0.011$, OR $=0.2248,95 \%$ CI $0.084-0.730)$ was negatively correlated with revascularization risk. After adjusting for all the possible risk factors, multivariate logistic regression analyses showed that current smoking $(P<0.001, \mathrm{OR}=3.238,95 \% \mathrm{CI} 1.716-6.112)$ and nonHDL-c $(P=0.001, \mathrm{OR}=1.983,95 \%$ CI $1.325-2.969)$ were independent risk factors for follow-up revascularization in TVD patients who underwent second-generation DES implantation (Table 2).

\section{Logistic regression analysis of risk factors for ISR}

Based on univariate logistic regression analysis, the risk factors for ISR included age $(P=0.030, \mathrm{OR}=1.040,95 \%$ CI 1.004-1.077), current smoking $(P=0.042$, OR $=1.990$, 95\% CI 1.024-3.868), CKD4-5 $(P=0.043$, OR $=4.062$, 95\% CI 1.044-15.807) and follow-up time $(P=0.012$, $\mathrm{OR}=1.015,95 \%$ CI 1.003-1.027). In multivariate logistic regression analyses after adjusting for all the possible risk factors, older age, current smoking and CKD4-5 were independent factors for predicting an increased occurrence of ISR $(P=0.004, \mathrm{OR}=1.060,95 \%$ CI $1.019-1.102$, $P=0.006, \mathrm{OR}=2.918,95 \% \mathrm{CI} 1.367-6.227$ and $P=0.042$, $\mathrm{OR}=4.985,95 \%$ CI 1.056-23.533, respectively) (Table 3).

\section{Receiver operating characteristic (ROC) curve analysis of risk factors for predicting revascularization and ISR} ROC curve analysis demonstrated that a non-HDL-C value of $2.52 \mathrm{mmol} / \mathrm{L}$ was the cutoff level based on the Youden index analysis, with a sensitivity and specificity

Table 2 Univariate and multivariate logistic regression analysis for risk factors related to revascularization in TVD patients after second generation DES implantation

\begin{tabular}{|c|c|c|c|c|c|c|}
\hline \multirow[t]{2}{*}{ Factors } & \multicolumn{3}{|c|}{ Univariate analysis } & \multicolumn{3}{|c|}{ Multivariate analysis } \\
\hline & OR & $95 \% \mathrm{Cl}$ & $P$ value & OR & $95 \% \mathrm{Cl}$ & $P$ value \\
\hline Current smoker & 2.605 & $1.499-4.529$ & 0.001 & 3.238 & $1.716-6.112$ & $<0.001$ \\
\hline $\mathrm{TC}$ & 1.591 & $1.145-2.211$ & 0.006 & - & - & NS \\
\hline$L D L-C$ & 2.153 & $1.354-3.423$ & 0.001 & - & - & NS \\
\hline HDL-C & 0.214 & $0.072-0.632$ & 0.005 & - & - & NS \\
\hline Non-HDL-C & 1.994 & $1.378-2.887$ & $<0.001$ & 1.983 & $1.325-2.969$ & 0.001 \\
\hline ApoB & 7.549 & $1.610-35.405$ & 0.010 & - & - & NS \\
\hline NEU & 1.301 & $1.066-1.588$ & 0.010 & - & - & NS \\
\hline Follow-up time & 1.017 & $1.006-1.027$ & 0.002 & - & - & NS \\
\hline
\end{tabular}

TVD triple-vessel disease, DES drug-eluting stents, CKD chronic kidney disease, $T C$ total cholesterol, $L D L-C$ low-density lipoprotein cholesterol, $H D L-C$ high-density lipoprotein cholesterol, non-HDL-C non-high-density lipoprotein cholesterol, $A p o B$ apolipoprotein $B, N E U$ neutrophil, OR odds ratio, CI confidence interval, NS no significant association $(P>0.05)$

Table 3 Univariate and multivariate logistic regression analysis of risk factors related to revascularization in TVD patients after secondgeneration DES implantation

\begin{tabular}{|c|c|c|c|c|c|c|}
\hline \multirow[t]{2}{*}{ Factors } & \multicolumn{3}{|c|}{ Univariate analysis } & \multicolumn{3}{|c|}{ Multivariate analysis } \\
\hline & OR & $95 \% \mathrm{Cl}$ & $P$ value & OR & $95 \% \mathrm{Cl}$ & $P$ value \\
\hline Age & 1.040 & $1.004-1.077$ & 0.030 & 1.060 & $1.019-1.102$ & 0.004 \\
\hline Current smoking & 1.990 & $1.024-3.868$ & 0.042 & 2.918 & $1.367-6.227$ & 0.006 \\
\hline CKD4-5 & 4.062 & $1.044-15.807$ & 0.043 & 4.985 & $1.056-23.533$ & 0.042 \\
\hline Follow-up time & 1.015 & $1.003-1.027$ & 0.012 & - & - & NS \\
\hline
\end{tabular}


of $60.6 \%$ and $63.5 \%$ (AUC $=0.631,95 \% \mathrm{CI}=0.562-$ $0.700, P<0.001$ ) (Fig. 2c). In the ROC curve analysis of age (AUC $=0.604,95 \% \mathrm{CI}=0.506-0.702, \quad P=0.032$ ), 67.5 years of age was determined to be a predictive cutoff point for ISR, with a sensitivity and specificity of $53.5 \%$ and $77.1 \%$, respectively (Fig. $2 \mathrm{~d}$ ).

\section{Discussion}

This retrospective study revealed several findings. First, the total incidence rate of revascularization was $57.7 \%$, and the rate of ISR was $17.5 \%$ in the long-term follow-up study. Second, late adverse events, such as late ISR and late revascularization, even very late ISR and revascularization, continue to occur beyond 1 year after secondgeneration DES implantation. Third, current smoking was an independent risk factor for both revascularization and in-stent restenosis. Higher non-HDL-c is independently related to revascularization, and older age and CKD4-5 are potential risk factors for ISR in TVD patients after second-generation DES implantation. Moreover, non-HDL-C and age displayed predictive power in revascularization and ISR, respectively.

Several randomized controlled trials demonstrated sustained benefit of DES without major safety concerns compared to BMS $[9,10]$. However, adverse events after DES implantation, such as revascularization and ISR, remain an important clinical problem. A prospective study indicated that any revascularization occurred in $16.5 \%$ of CAD patients at 6 years [11]. Another registered study showed that the cumulative incidence of any revascularization in CAD patients was $38.6 \%$ at 5 years [12]. In our study, the cumulative rate $(57.7 \%)$ of revascularization was greater than that in the abovementioned studies. The possible reasons were as follows: First, all individuals included in the study were TVD patients, and these patients are classified as high-risk CAD patients. Second, the follow-up time was longer than that in previous studies, and more risk factors may accumulate with the prolonged follow-up time. Third, 202 (82.1\%) patients received follow-up CAG due to angina pectoris or precordial distress, which may cause the increased incidence of revascularization. The incidence of in-stent restenosis varied in different studies. One clinical study showed that at 2 years, the cumulative incidence of restenosis was $20 \%$ in CAD patients [13], and another study concluded that the incidence of restenosis in three-vessel disease was $20.9 \%$, with a mean $45.6 \pm 21.5$ months [14]. In the present study, the rate of ISR was $17.5 \%$, with a median of $28.0(14.0,56.0)$ months. Our study showed that the ISR data were comparable.

Studies have indicated an increase in the incidence of revascularization and ISR over time across different generations of DESs $[15,16]$. Late and very late ISR continued to occur constantly without attenuation up to 5 years after DES implantation [12]. Our present study demonstrated that angiographic stenotic progression (revascularization and ISR) was a continuous hazard, and a late catch-up phase occurs at $5+$ years after secondgeneration DES implantation. After stent implantation, fibrin deposition substitution for smooth muscle cells was the main process of neointima healing, and the best predictor of neointima was a 20-month follow-up period after drug stent implantation [17]. Progressive neointima may lead to neoatherosclerosis with a median stent duration of 420 days and contribute to angiographic stenotic progression [18]. It is worth noting that the trend of revascularization and ISR rates after DES implantation in our study can be explained by the abovementioned mechanism.

Plaque rupture and subsequent injury response facilitate the accretion of the vascular wall, contributing to angiographic stenotic progression. Patients who smoke after PCI have more rupture-prone unstable plaques and angina than patients who do not smoke [19]. Therefore, smoking may cause angiographic stenotic progression in patients. Although published studies have reported conflicting results about the relationship between smoking and revascularization or ISR in CAD patients after stent implantation [20-22], our results suggested that smoking after DES implantation served as a risk factor for revascularization and ISR $(\mathrm{OR}=1.990,95 \%$ CI $1.024-1.077$ and $\mathrm{OR}=2.717,95 \% \mathrm{CI} 1.268-5.821$, respectively) in TVD patients.

Non-HDL-c was calculated by subtracting the HDL-c level from the TC level, and we demonstrated that nonHDL-c may be a potential predictor of risk for revascularization in TVD patients after second-generation DES stent implantation (AUC $=0.631, P<0.001$ ). Non-HDL-c encompasses not only LDL-C, intermediate density lipoprotein and lipoprotein (a) but also very low-density lipoprotein cholesterol (VLDL-c), which can aid in increased predictive power. Moreover, non-HDL-c was considered a surrogate for LDL particle number (LDL-P) assessed by either apoB or nuclear magnetic resonance (NMR) spectroscopy [23, 24]. Furthermore, non-HDL-c can be calculated in the nonfasting state or in the setting of hypertriglyceridemia, which is convenient for capturing lipid-associated risk prediction.

On the basis of the results, we verified older age as a predictor of ISR by logistic regression analysis and ROC curve analysis (AUC $=0.604, P=0.032$ ). Older age can independently predict the risk for ISR after stent implantation $[25,26]$. Elderly patients with frequent and numerous comorbidities consistently exhibit decreased anticoagulant ability and thicker arterial walls, which makes them fragile with different 
phenotypes. Different phenotypes are differently associated with adverse events. What is more, elderly patients had a higher risk of being rehospitalized than younger patients, as well demonstrated in REPOSI study [27]. And these features contribute to the tendency to develop atherosclerosis and lead to restenosis. In addition, we observed that CKD4-5 was independently correlated with ISR risk. Patients with severe CKD or end-stage renal disease have a significantly higher risk of target lesion failure after second-generation DES implantation [28]. CKD is accompanied by high oxidative stress, endothelial dysfunction, and an inflammatory status and independently predicts neoatherosclerosis [29]. These factors can increase the risk of ISR in patients after DES implantation.

Diabetes mellitus (DM), which is generally considered an established risk factor for revascularization and in-stent restenosis after stent implantation [30], was not found to be an independent revascularization or ISR risk factor in our study. It has been reported that patients with $\mathrm{DM}$ and $\mathrm{HbA} 1<7.0 \%$ undergoing stenting may benefit from reducing the risk of restenosis and experience lower rates of repeat revascularization [31]. And it was observed that intense glycemic control can improve the cardiovascular outcome after acute coronary syndrome even in non-diabetic hyperglycemic subjects [32,33]. We believe that the low HbA1c level in our patients [median HbA1c $6.4 \%(5.8,7.8)$ in the revascularization group and the median HbA1c $6.4 \%(6.0,8.4)$ in the ISR group might be an important reason.

Accessing site crossover have been also associated with an increased risk of procedural failure and revascularization [34, 35]. The previous procedure was started via transradial approach in most of patients in our study. Few patients with complex lesions, such as chronic total occlusion received crossover (from transradial approach to transfemoral approach), some of them were recommended to undergo $C A B G$ surgery according to the result of CAG, which can contribute to reduce risk of procedural failure and revascularization.

\section{Limitations}

This retrospective study still had some limitations. First, there was a lack of randomization, and the included patients were from a single center. Second, the number of patients included was relatively small, especially the sample of patients with ISR, and numerous of risk factors were included in the analysis, which might reduce the statistical power. Moreover, the correlation of other oral drugs that are related to CAD with revascularization and ISR was not investigated. Finally, the results of this study cannot be generalized to a younger population.

\section{Conclusion}

In summary, our study demonstrated that a high risk of revascularization and ISR continues to exist in TVD patients after second-generation DES implantation, and angiographic stenotic progression (revascularization and ISR) is the continuous hazard. In addition, current smoking was an independent risk factor for both revascularization and in-stent restenosis. Higher non-HDL-c is independently related to revascularization. Moreover, older age and CKD4-5 are potential risk factors for ISR in TVD patients after second-generation drugeluting stent implantation. For these patients, intense management of changes in lifestyle and better medical measures are needed to control risk factors. More clinical trials are needed to focus on these patients to elucidate high-risk factors for revascularization and ISR and to improve progress.

\section{Abbreviations \\ TVD: triple-vessel disease; ISR: in-stent restenosis; DES: drug-eluting stent; BMS: bare-metal stent; CKD: chronic kidney disease; HDL-c: high-density lipoprotein cholesterol; CAD: coronary artery disease; LAD: left anterior descending artery; LCX: left circumflex artery; RCA: right coronary artery; LM: left main coronary artery disease; MACEs: major adverse cardiac events; $\mathrm{PCl}$ : percutaneous coronary intervention; DAPT: dual antiplatelet therapy; CAG: coronary angi- ography; CABG: coronary artery bypass graft; OR: odds ratios; Cl: confidence intervals; ROC: receiver operating characteristic; AUC: area under the curve; BMI: body mass index; SBP: systolic blood pressure; DBP: diastolic blood pres- sure; TC: total cholesterol; LDL-C: low-density lipoprotein cholesterol; HDL-C: high-density lipoprotein cholesterol; ApoB: apolipoprotein B; NEU: neutrophil; LY: Iymphocyte; NLR: neutrophil-to-lymphocyte ratio; WBC: white blood cell; Hs-CRP: high-sensitivity C-reactive protein; HbA1c: glycosylated hemoglobin A1c; HCY: homocysteine; SUA: serum uric acid; DM: diabetes mellitus.}

\section{Acknowledgements}

Not applicable.

\section{Authors' contributions}

MYZ conceived the study. MYZ performed statistical analysis and drafted the manuscript. WW and XWY critically revised and reviewed the manuscript. All authors read and approved the final manuscript.

Funding

There was no funding source.

Availability of data and materials

All data generated or analyzed during the study are in the article.

\section{Declarations}

Ethics approval and consent to participate

The authors were granted approval from the Ethics Committee of Peking Union Medical College Hospital to obtain and use the collected data for analysis, and written informed consent was obtained from all patients.

Consent for publication

Not applicable.

Competing interests

The authors declare that there have no competing interests.

Received: 13 June 2021 Accepted: 31 August 2021

Published online: 17 September 2021 


\section{References}

1. de Waha S, Eitel I, Desch S, Fuernau G, Pöss J, Schuler G, et al. Impact of multivessel coronary artery disease on reperfusion success in patients with ST-elevation myocardial infarction: a substudy of the AIDA STEMI trial. Eur Heart J Acute Cardiovasc Care. 2017:6(7):592-600.

2. Zeymer U, Vogt A, Zahn R, Weber MA, Tebbe U, Gottwik M, et al. Predictors of in-hospital mortality in 1333 patients with acute myocardial infarction complicated by cardiogenic shock treated with primary percutaneous coronary intervention $(\mathrm{PCl})$; results of the primary $\mathrm{PCl}$ registry of the Arbeitsgemeinschaft Leitende Kardiologische Krankenhausärzte (ALKK). Eur Heart J. 2004;25(4):322-8.

3. Mahmoud AN, Shah NH, Elgendy IY, Agarwal N, Elgendy AY, Mentias A, et al. Safety and efficacy of second-generation drug-eluting stents compared with bare-metal stents: an updated meta-analysis and regression of 9 randomized clinical trials. Clin Cardiol. 2018;41(1):151-8.

4. Stefanini GG, Holmes DR Jr. Drug-eluting coronary-artery stents. N Engl J Med. 2013;368(3):254-65.

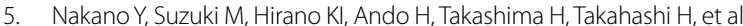
Association of triglyceride deposit cardiomyovasculopathy with drugeluting stent restenosis among patients with diabetes. JAMA Netw Open. 2020;3(8):e2012583.

6. Unoki T, Wada H, Akao M, Ura S, Takabayashi K, Yamashita Y, et al. Abstract 14787: inverse association of vascular endothelial growth factor-c with the risk of restenosis and cardiovascular events after drug-eluting stent implantation. Circulation. 2013;128(suppl_22):A14787.

7. Spitzer E, Frei M, Zaugg S, Hadorn S, Kelbaek H, Ostojic M, et al. Rehospitalizations following primary percutaneous coronary intervention in patients with ST-elevation myocardial infarction: results from a multi-center randomized trial. J Am Heart Assoc. 2017:6(8):e005926.

8. Tarantini G, D’Amico G, Brener SJ, Tellaroli P, Basile M, Schiavo A, et al. Survival after varying revascularization strategies in patients with STsegment elevation myocardial infarction and multivessel coronary artery disease: a pairwise and network meta-analysis. JACC Cardiovasc Interv. 2016;9(17):1765-76.

9. Mauri L, Massaro JM, Jiang S, Meredith I, Wijns W, Fajadet J, et al. Long-term clinical outcomes with zotarolimus-eluting versus bare-metal coronary stents. JACC Cardiovasc Interv. 2010;3(12):1240-9.

10. Vink MA, Dirksen MT, Suttorp MJ, Tijssen JG, van Etten J, Patterson MS, et al, 5-year follow-up after primary percutaneous coronary intervention with a paclitaxel-eluting stent versus a bare-metal stent in acute ST-segment elevation myocardial infarction: a follow-up study of the PASSION (paclitaxeleluting versus conventional stent in myocardial infarction with ST-segment elevation) trial. JACC Cardiovasc Interv. 2011;4(1):24-9.

11. Bønaa KH, Mannsverk J, Wiseth R, Aaberge L, Myreng Y, Nygård O, et al. Drug-eluting or bare-metal stents for coronary artery disease. N Engl J Med. 2016;375(13):1242-52.

12. Kimura T, Morimoto T, Nakagawa Y, Kawai K, Miyazaki S, Muramatsu T, et al. Very late stent thrombosis and late target lesion revascularization after sirolimus-eluting stent implantation: five-year outcome of the j-cypher registry. Circulation. 2012;125(4):584-91.

13. Mehilli J, Kastrati A, Byrne RA, Bruskina O, lijima R, Schulz S, et al. Paclitaxelversus sirolimus-eluting stents for unprotected left main coronary artery disease. J Am Coll Cardiol. 2009;53(19):1760-8.

14. Berta B, Ruzsa Z, Barczi G, Becker D, Geller L, Jambrik Z, et al. Long-term clinical follow-up after drug-eluting stent implantation for bare metal in-stent restenosis. J Interv Cardiol. 2013;26(3):271-7.

15. Brener SJ, Kereiakes DJ, Simonton CA, Rizvi A, Newman W, Mastali K, et al. Everolimus-eluting stents in patients undergoing percutaneous coronary intervention: final 3-year results of the clinical evaluation of the XIENCE V everolimus eluting coronary stent system in the treatment of subjects with de novo native coronary artery lesions trial. Am Heart J. 2013;166(6):1035-42.

16. Natsuaki M, Morimoto T, Furukawa Y, Nakagawa Y, Kadota K, Yamaji K, et al. Late adverse events after implantation of sirolimus-eluting stent and baremetal stent: long-term (5-7 years) follow-up of the coronary revascularization demonstrating outcome study-Kyoto registry cohort-2. Circ Cardiovasc Interv. 2014;7(2):168-79.

17. Kang SJ, Mintz GS, Akasaka T, Park DW, Lee JY, Kim WJ, et al. Optical coherence tomographic analysis of in-stent neoatherosclerosis after drug-eluting stent implantation. Circulation. 2011;123(25):2954-63.
18. Nakazawa G, Otsuka F, Nakano M, Vorpahl M, Yazdani SK, Ladich E, et al. The pathology of neoatherosclerosis in human coronary implants bare-metal and drug-eluting stents. J Am Coll Cardiol. 2011;57(11):1314-22.

19. Jang JS, Buchanan DM, Gosch KL, Jones PG, Sharma PK, Shafiq A, et al. Association of smoking status with health-related outcomes after percutaneous coronary intervention. Circ Cardiovasc Interv. 2015;8(5):e002226.

20. Rittersma SZ, de Winter RJ, Koch KT, Schotborgh CE, Bax M, Heyde GS, et al. Preprocedural C-reactive protein is not associated with angiographic restenosis or target lesion revascularization after coronary artery stent placement. Clin Chem. 2004;50(9):1589-96.

21. Cohen DJ, Doucet M, Cutlip DE, Ho KK, Popma JJ, Kuntz RE. Impact of smoking on clinical and angiographic restenosis after percutaneous coronary intervention: another smoker's paradox? Circulation. 2001;104(7):773-8.

22. Zhang YJ, lqbal J, van Klaveren D, Campos CM, Holmes DR, Kappetein AP, et al. Smoking is associated with adverse clinical outcomes in patients undergoing revascularization with PCI or CABG: the SYNTAX trial at 5-year follow-up. J Am Coll Cardiol. 2015;65(11):1107-15.

23. Jeyarajah EJ, Cromwell WC, Otvos JD. Lipoprotein particle analysis by nuclear magnetic resonance spectroscopy. Clin Lab Med. 2006;26(4):847-70.

24. Cromwell WC, Otvos JD, Keyes MJ, Pencina MJ, Sullivan L, Vasan RS, et al. LDL particle number and risk of future cardiovascular disease in the framingham offspring study: implications for LDL management. J Clin Lipidol. 2007; 1(6):583-92

25. Asamasu-Sato S, Mita M, Ogawa R, Isaka M, Saito M. Analysis of clinical factors that influence re-stenosis after percutaneous coronary stenting. Yakugaku zasshi J Pharm Soc Jpn. 2007;127(8):1309-15.

26. Paramasivam G, Devasia T, Jayaram A, Rao MS, Vijayvergiya R, et al. In-stent restenosis of drug-eluting stents in patients with diabetes mellitus: clinical presentation, angiographic features, and outcomes. Anatol J Cardiol. 2020;23(1):28-34

27. Marcucci M, Franchi C, Nobili A, Mannucci PM, Ardoino I. Defining aging phenotypes and related outcomes: clues to recognize frailty in hospitalized older patients. J Gerontol A Biol Sci Med Sci. 2017;72(3):395-402.

28. Lee JM, Kang J, Lee E, Hwang D, Rhee TM, Park J, et al. Chronic kidney disease in the second-generation drug-eluting stent era: pooled analysis of the Korean multicenter drug-eluting stent registry. JACC Cardiovasc Interv. 2016;9(20):2097-109.

29. Yonetsu T, Kato K, Kim SJ, Xing L, Jia H, McNulty I, et al. Predictors for neoatherosclerosis: a retrospective observational study from the optical coherence tomography registry. Circ Cardiovasc Imaging. 2012;5(5):660-6.

30. Kedhi E, Généreux P, Palmerini T, McAndrew TC, Parise H, Mehran R, et al. Impact of coronary lesion complexity on drug-eluting stent outcomes in patients with and without diabetes mellitus: analysis from 18 pooled randomized trials. J Am Coll Cardiol. 2014;63(20):2111-8.

31. Hwang JK, Lee SH, Song YB, Ahn J, Carriere K, Jang MJ, et al. Glycemic control status after percutaneous coronary intervention and long-term clinical outcomes in patients with type 2 diabetes mellitus. Circ Cardiovasc Interv. 2017;10(4):e004157

32. Marfella R, Sasso FC, Cacciapuoti F, Portoghese M, Rizzo MR, Siniscalchi M, et al. Tight glycemic control may increase regenerative potential of myocardium during acute infarction. J Clin Endocrinol Metab. 2012;97(3):933-42.

33. Sasso FC, Rinaldi L, Lascar N, Marrone A, Pafundi PC, Adinolfi LE, et al. Role of tight glycemic control during acute coronary syndrome on CV outcome in type 2 diabetes. J Diabetes Res. 2018;2018:3106056.

34. Gragnano F, Branca M, Frigoli E, Leonardi S, Vranckx P, Di Maio D, et al. Access-site crossover in patients with acute coronary syndrome undergoing invasive management. JACC Cardiovasc Interv. 2021;14(4):361-73.

35. Abdelaal E, MacHaalany J, Plourde G, Barria Perez A, Bouchard MP, Roy M, et al. Prediction and impact of failure of transradial approach for primary percutaneous coronary intervention. Heart. 2016;102(12):919-25.

\section{Publisher's Note}

Springer Nature remains neutral with regard to jurisdictional claims in published maps and institutional affiliations. 